\title{
Diabetic Nephropathy: Review of Novel Experimental and Clinical Strategies
}

\section{Original Article}

\author{
Amal M. Mahfoz ${ }^{1,2}$, Nahed M. Hassanein ${ }^{2}$, Afaf A. Shoka ${ }^{3}$ and Hekma A. Abd El- \\ Latif $^{1,3}$
}

${ }^{I}$ Department of Pharmacology and Toxicology, Faculty of Pharmacy, Modern University for Technology and Information, Cairo, ${ }^{2}$ Department of Developmental Pharmacology, National Organization for Drug Control and Research (NODCAR), Giza, ${ }^{3}$ Faculty of Pharmacy, Cairo University, Cairo, Egypt.

\begin{abstract}
Background: Diabetic nephropathy (DN) is considered a severe disorder which affects health worldwide. New more active treatment options are required. Despite a large number of drugs already being available for treatment of hyperglycemia in diabetes, current oral antidiabetic agents often do not provide adequate glycemic control. Renin-angiotensin-aldosterone system (RAAS) blockers are novel agents to slow the progression of DN.

Method: The present review provides an overview of recent studies on DN management, especially the use RAAS blockers and their antidiabetic effects. References were mainly identified through PubMed search until December 2016 and backtracking of references in pertinent studies.

Results: This review reporting the novel mechanisms and benefits of targeting the RAAS by the use of ACEIs; ARB or direct renin inhibitors in glucose lowering, antioxidant and anti-inflammatory effects and kidney protection.

Conclusion: These drugs targeting the RAAS can be used as monotherapy or in combination therapy in hypertensive-diabetic patients to protect them from $\mathrm{DN}$.
\end{abstract}

Received: 15 August, 2018, Accepted: 28 November, 2018.

Key Words: ACEIs; aliskiren; diabetic nephropathy; RAAS.

Corresponding Author: Amal M. Mahfoz, Department of Developmental Pharmacology, National Organization for Drug Control and Research (NODCAR), Egypt, Tel.: +20 1064798943, E-mail: mahfozamal@gmail.com.

Bulletin of Faculty of Pharmacy, Cairo University, ISSN: 1110-0931, Vol. 57, No. 2

\section{BACKGROUND}

Diabetic nephropathy (DN) is considered the major dangerous complication of both type I and II diabetes. Its complications severely influence the patient life and it is considered the main cause of renal failure, even in developed or non-developed countries. Early treatment delays or prevents these severe complications. Preclinical studies on experimental animals are important for discovery of new molecules or treatment strategies.

The pathophysiology of DN is involved high blood pressure (BP), fluid retention, continuous albuminuria, decreased glomerular filtration rate (GFR), and glomerulosclerosis because of end stage renal disease (ESRD). Elevated oxidative stress and inflammatory mediators are involved in the underlined mechanism of $\mathrm{DN}^{[1-4]}$. In addition to decrease antioxidant defense mechanisms; kidney nitric oxide synthase (NOS) reported to be decreased in experimental $\mathrm{DN}^{[5]}$. Numerous endogenous modulators as endothelin- $\mathrm{I}^{[6]}$, angiotensin $\mathrm{II}^{[7]}$, arginine vasopressin ${ }^{[8]}$, urotensin- $\mathrm{II}^{[9]}$, asymmetric dimethylarginine ${ }^{[10]}$, caveolin ${ }^{[11]}$, C-reactive $\operatorname{protein}^{[12]}$, and leptin $^{[13]}$ have been reported with DN. In addition to many other factors intermediate the evolution of nephropathy in diabetic patients includes hyperglycemia, atherosclerosis and hypertension ${ }^{[14]}$ (Figure 1).

\section{EXPERIMENTAL MODELS OF NEPHROPATHY}

Increasing number of patients with ESRD who need dialysis lead to the evolution of many animal models to study the different mechanisms underlying nephropathy and to develop new drugs for treatment ${ }^{[15]}$.

\section{Induction of diabetes nephropathy}

\section{Streptozotocin (STZ)}

Streptozotocin is an alkylating agent; nitrosourea class; used in treatment of Islets of Langerhans cancer. The mechanism of action of STZ is by damage of pancreatic $\beta$-cells of the Islets of Langerhans by damages the DNA, so it is used in induction of diabetes in animals. Single dose of STZ in rats $(40,50,55,60 \mathrm{or} 65 \mathrm{mg} / \mathrm{kg}$ i.p. or i.v.) leads to hyperglycemia in 72 hours ${ }^{[15,16]}$. Nephropathy observed in rats in 1-2 months after induction. DN is showed by critical rise in serum creatinine level, blood urea nitrogen (BUN), and glomerulosclerosis ${ }^{[15]}$. STZ-induced DN leads to decrease eNOS activity and decrease NO, which triggers nephropathy. Szabo et al., ${ }^{[17]}$ noted that STZ administration 

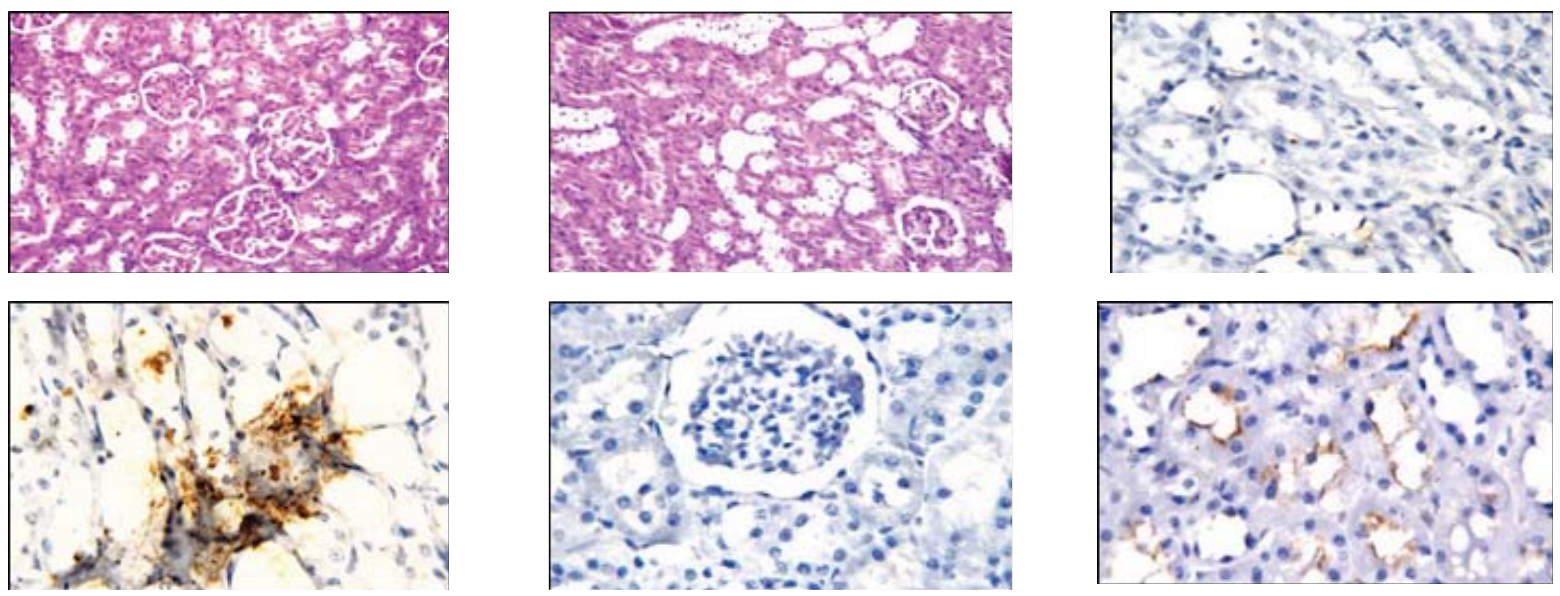

Fig. 1 (a-f): Photomicrographs for kidney sections from normal rats and rats with diabetic nephrotoxicity induced by streptozotocin (fig. 1a, 1b: H\&E-stained; fig. $1 \mathrm{c}, 1 \mathrm{~d}$ : immunohistochemistry staining for determination of Caspase 3 ; fig 1e, 1f: immunohistochemistry staining for determination of TGF- $\beta)(\times 200)$ (Mahfoz et al., 2016).

1a: Kidney of rat in normal control group: showing normal histological structures of the glomeruli and tubules of the cortex. 1b: Kidney of rat in diabetic control group: showing degeneration and coagulative necrosis in lining epithelial cells of some individual tubules at the cortex. Fig. 1c: kidney of rat in normal control group showing negative immunoreaction using caspase 3. Fig. 1d: Kidney of rat in diabetic control group showing strong positive immunoreaction using caspase 3. Fig. 1e: Kidney of rat in normal control group showing negative immunoreaction using TGF- $\beta$. Fig. 1f: Kidney of rat in diabetic control group showing mild immunoreaction using TGF- $\beta$.

( $35 \mathrm{mg} / \mathrm{kg}$ i.p., once) in rats in which $1 / 2$ kidney is resected and the other one removed, lead to macro albuminuria in 80 days, with significant increase in triglycerides, serum creatinine and glomerulosclerosis ${ }^{[18]}$. In mice; STZ (125 $\mathrm{mg} / \mathrm{kg}$ i.p.) administration for 2 days induced $\mathrm{DN}^{[19]}$. STZinduced DN is a common used model in experimental studies; DN appeared within 4-6 weeks after a single $\operatorname{dose}^{[17]}$.

\section{Genetic model}

Important, non-obese model for studying molecular basis of DN using: Goto-Kakisaki (GK) rat. It is characterized by hyperglycemia; at age 24 months nephropathy appeared ${ }^{[20]}$.

\section{Cyclosporine A-induced nephropathy}

Cyclosporine is an immunosuppressant and inhibitor of calcineurin. It is not used clinically because of its nephropathy side effect ${ }^{[21]}$. Administration of $7.5 \mathrm{mg} / \mathrm{kg} /$ day or $15 \mathrm{mg} / \mathrm{kg} /$ day s.c. of cyclosporine in rats lead to nephropathy ${ }^{[7,22]}$.

\section{Anthracycline-induced nephropathy}

Doxorubicin is an anthracycline antibiotic. Due to its toxicity on heart and kidney, it is used now as anticancer drug for breast, bladder, thyroid and stomach cancer. Doxorubicin used in dose of $2 \mathrm{mg} / \mathrm{kg}$ i.v., two times per day for 5 months to induce rats' nephropathy. While $20 \mathrm{mg} /$ $\mathrm{kg}$ i.v. once in mice developed serious nephropathy ${ }^{[23,24]}$.

\section{Electrolyte nephropathy}

Abnormalities of electrolytes level in kidney was found to induced nephropathy due to dysfunction of nephron which caused mainly by decrease $\mathrm{Mg}^{2+}$ and $\mathrm{K}^{+}$content. Disodium hydrogen phosphate diet for rats, for 12 days induces nephropathy ${ }^{[25]}$.

\section{Ethylene glycol model of nephropathy}

Ethylene glycol was used as antifreeze material in cooling systems. $50-400 \mathrm{mg} / \mathrm{kg} /$ day ethylene glycol p.o. for 12 months induced nephropathy. This is due to oxalic acid; which is the metabolic product of ethylene glycol. Oxalic acid precipitated as crystals in kidney. This resulted in increased ROS and renal degeneration ${ }^{[26]}$.

\section{Aminoglycoside-induced nephropathy}

Nephrotoxicity is a severe side effect of gentamicin which limits its use. Kumar et al., (2000) ${ }^{[27]}$ reported that ( $80 \mathrm{mg} / \mathrm{kg}$, i.p.; gentamicin) for one week in rats induced nephropathy associated with high ROS.

\section{Cadmium model of nephropathy}

Cadmium is used in metal coatings but chronic exposure lead to nephrotoxicity ${ }^{[28]}$. Uriu et al., (1998) ${ }^{[29]}$ reported that $0.18 \mathrm{mg} / \mathrm{kg}$ i.p., of cadmium 3 times per week for 3 months in rats induced nephropathy.

\section{Carbon tetrachloride-induced nephropathy}

Chronic exposure to carbon tetrachloride $(\mathrm{CCl} 4)$ is hepatotoxic and nephrotoxic due to its metabolic end products $^{[30]}$. Administration of $0.5 \mathrm{ml} / \mathrm{kg}$ s.c., of CCl4, 3 times per week for 7 weeks induced nephropathy in rats ${ }^{[31]}$.

\section{Germanium dioxide (GeO2) model of nephropathy}

$\mathrm{GeO} 2$ is used as additive in foods, medicines, and cosmetics. For its anti-microbial, anti-tumor and immunomodulatory properties. Yanagisawa et al., (2000) 
reported that $5.16 \mathrm{~g} /$ day of $\mathrm{GeO} 2$ in diet for rats for 5 months developed nephropathy ${ }^{[32]}$.

\section{Mercury chloride (HgCl2) induced nephropathy}

$\mathrm{HgCl} 2(1 \mathrm{mg} / \mathrm{kg}$ s.c.) resulted in DN in rats when used on days $0,2,4,7,9$ and $11^{[33]}$.

\section{Cisplatin model of nephropathy}

It is an anticancer agent. $7 \mathrm{mg} / \mathrm{kg}$ iv, once was reported to induce nephropathy in rats within one week ${ }^{[34]}$.

\section{Vomitoxin model of nephropathy}

Vomitoxin is got from the fungus Fusarium graminearum. This fungus is grown on wheat and maize. It causes renal failure among kids and young. $25 \mathrm{mg} / \mathrm{kg}$ of vomitoxin, $\mathrm{PO}$, one time per day was found to induce nephropathy in mice ${ }^{[35]}$.

\begin{tabular}{lll} 
NEW BIOMARKERS & FOR \\
\hline NEPHROPATHY
\end{tabular}

Albuminuria is the gold standard biomarker of DN. However albuminuria has some limitations as large variability and low sensitivity ${ }^{[36]}$. So novel biomarkers for $\mathrm{DN}$ are very important for early diagnosis or treatment evaluation, are the following:

\section{Cystatin C}

Cystatin C, a protease inhibitor, is a low molecular weight protein, freely filtered by glomeruli. Urinary cystatin $\mathrm{C}$ level early increased in Zucker diabetic fatty rats before severe renal damage ${ }^{[37]}$.

\section{Immunoglobulins}

Urinary $\operatorname{IgM}$ or $\operatorname{IgG}$ excretion marks that a damage or large pore present in the glomerular capillary wall. It considered an early predictor of progression of type 1 $\mathrm{DN}^{[38,39]}$.

\section{Type IV collagen}

Increased collagen excretion in urine is observed to be increased in type $2 \mathrm{DN}^{[40]}$.

\section{Podocytes and podocyte-associated molecules}

Podocytes are structural components of glomerular barrier. Urinary excretion of podocytes is considered an early potential marker of $\mathrm{DN}^{[41,42]}$.

\section{Transferrin}

Transferrin is a plasma protein, more filtered through glomerular filteration barrier than albumin ${ }^{[38]}$. Urinary transferrin excretion is considered an early potential marker for early detection of DN.

\section{Ceruloplasmin}

Ceruloplasmin is plasma copper-carrying protein. Urine excretion of ceruloplasmin reported even in normoalbumin-urea diabetic patients ${ }^{[43]}$.

\section{Transforming Growth Factor - $\beta$ (TGF- $\beta)$}

TGF- $\beta$ is considered an important growth factor ${ }^{[44]}$. It is observed to be increased in type 1 and $2 \mathrm{DN}^{[45,46]}$. TGF- $\beta$ is even elevated in normo-albumin-uric diabetic patients; it is considered an important biomarker for the pathogenesis of $\mathrm{DN}^{[47]}$.

\section{Oxidative stress biomarkers}

Elevated serum Malondialdehyde (MDA) and Nitric oxide (NO) and decreased serum superoxide dismutase activity (SOD) are reported in $\mathrm{DN}^{[48-50]}$.

Inflammation biomarkers: TNF- $\alpha, M C P-1, I L-6$, VDBP

Previous studies showed that pro-inflammatory cytokines like TNF- $\alpha^{[48]}$, Vitamin D-Binding Protein (VDBP) $)^{[51]}$ and IL-6 ${ }^{[52]}$ were reported in DN.

\section{MANAGEMENT OF DIABETIC NEPHROPATHY}

There are several lines in treatment of patients with DN. Hyperglycemia control, lowering of elevated blood pressure, and decreasing salt in diet slow the progression and complications of DN.

Role of renin angiotensin aldosterone system (RAAS) in DN

RAAS is known by its significant role in controlling cardiovascular homeostasis. RAAS rely on the biotransformation of angiotensinogen (Ang) to angiotensin I (Ang I) and Ang II by the effect of angiotensin converting enzyme (ACE) ${ }^{[53]}$. Ang II function is mediated through Angiotensin 1 receptor (AT1R) and Angiotensin 2 receptor (AT2R). Functions of Ang II include: proinflammatory, prooxidative, vasoconstriction, hypertrophic and proliferative $\operatorname{effects}^{[53]}$ (Figure 2).

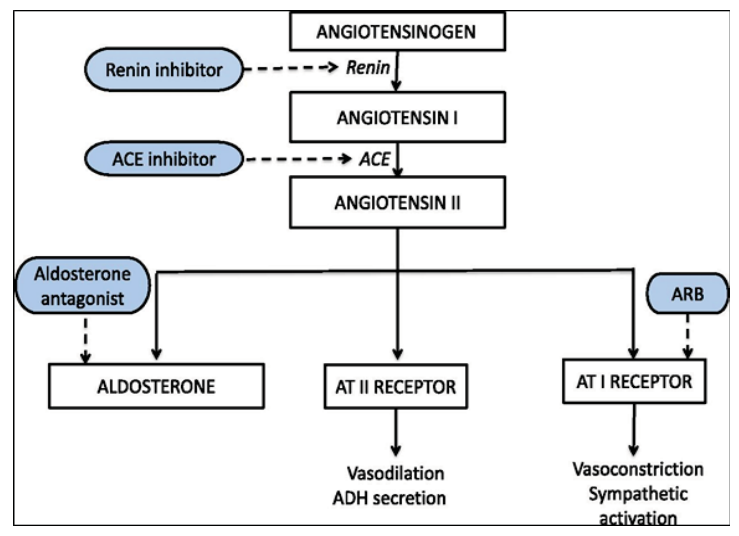

Fig. 2: Flowchart showing the clinical effects of RAAS and the sites of action of ACEIs, Renin inhibitors and ARBs.

RAAS is found in all tissue, including the blood vessels, heart, kidney, brain, and skeletal muscles pancreas, adipose tissue ${ }^{[54]}$. Insulin resistance and pancreatic $\beta$ cell 
dysfunction are correlated to RAAS function ${ }^{[55]}$. The negative feedback effect of Ang II on AT1R is the main mechanism responsible for RAAS harmful effects ${ }^{[56]}$.

Insulin resistance is reported to decrease by increase ACE2/Ang/Mas receptor axis. ACE2 gene therapy also enhances hyperglycemia control in diabetic mice due to its observed ability to elevate the action of bradykinin ${ }^{[54,57]}$ (Figures 2, 3). Furthermore, bradykinin influences insulin production and effect. It is resulted in $\beta$ cell injury and affects the transcriptional expression of glucose transporter 2(GLUT2) $)^{[58-60]}$.

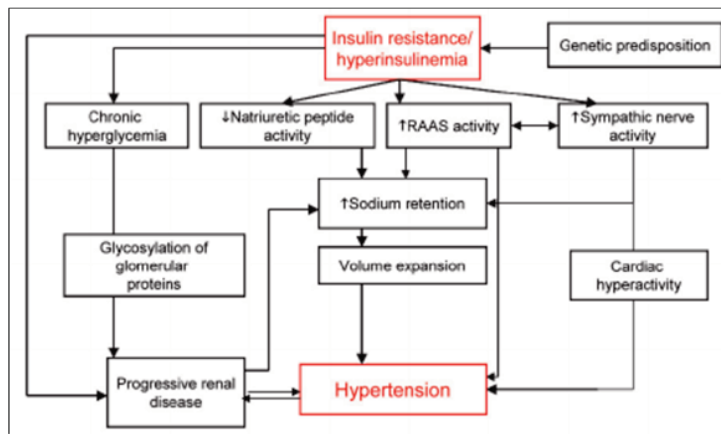

Fig. 3: Relation between insulin resistance, RAAS and hypertension.

\section{Antidiabetic mechanisms of ACEIs and ARBs:}

Increasing spread of metabolic syndrome and type 2 diabetes has generated interest in metabolic effects of antihypertensive drugs. The main focus was on the effects of diuretics and beta-blockers on carbohydrate and lipid metabolism $^{[61,62]}$.

Previous recent studies have reported the ability of some new antihypertensive agents to lead to less metabolic sideeffects than diuretics, and also decrease the risk for type 2 diabetes. Drugs with antidiabetic and antihypertensive effects are considered more important clinically ${ }^{[63,64]}$.

Previous clinical, preclinical, in-vitro and in-vivo studies which involved the inhibition RAAS have reported a potential relation between RAAS and insulin resistance. AngII may enhance glucose digestion by its consequences for insulin flagging pathways, tissue blood stream, sympathetic effects and oxidative pressure ${ }^{[65-67]}$

ACEIs or ARBs may enhance glucose digestion by interference with AngII age or AngII receptor initiation. To be sure, given a portion of the confirmation collected to date, it is conceivable that pharmacologic of the meddling RAAS may some time or another demonstrate fit for enhancing insulin affectability and diminishing the hazard for diabetes. Late preclinical and clinical investigations have announced that ACEIs may build insulin affectability ${ }^{[65,67]}$.

The consequences of these investigations are fascinating to propel trials to ponder the capacity of ACEIs to diminish the occurrence of new-beginning type 2 diabetes $^{[62,68]}$. Past examinations recommended that the antidiabetic properties of ACEIs might be through increments in nitric oxide, bradykinin level and GLUT4 glucose transporter ${ }^{[65,69,70]}$.

Beyond examinations in rats missing bradykinin B2 receptors and in rats dealt with an ACEI and a bradykinin antagonist proposed that the insulin-sharpening impacts of ACEIs encompass something other than decreases in Ang II tiers ${ }^{[65,70]}$. Increments in bradykinin level from changing over compound hindrance may enhance glucose digestion by influencing insulin flagging pathways, nitric oxide creation and translocation of GLUT4 ${ }^{[69,71]}$.

To the degree that the antidiabetic impacts of ACEIs are auxiliary to impedance with Ang II-subordinate systems that advance insulin protection, one may anticipate that ARBs will be more successful than ACEIs in enhancing insulin protection and avoiding type 2 diabetes. Paolisso et al., (1997) ${ }^{[72]}$ noticed that losartan-initiated increments in entire body glucose transfer were associated with losartan-prompted increments in femoral supply route bloodstream. Nonetheless, few examinations have been manufactured from the insulin-polishing influences of ACEIs as opposed to ARBs and, to this point, no sizeable scale clinical trials have checked out the ability of ACEIs and ARBs to diminish the danger for diabetes ${ }^{[73-75]}$.

Some examiners have encouraged that the inhibitory impacts of AngII on insulin-flagging pathways won't be intervened via both kind 1 or kind 2 Ang II receptors and that some other sort of Ang receptor is probably covered ${ }^{[76]}$.

Clinical trials utilizing ARBs have given some aberrant help to the likelihood that Ang II receptor barricade may enhance insulin affectability and decline the rate of type 2 diabetes $^{[77]}$.

ACEIs or ARBs are renoprotective and slight strengthen of endless nephropathies in animals and sufferers. However, they have little impact on basal glucose and insulin stages, in animals ${ }^{[78]}$.

\section{Renin Inhibitors}

Renin is the foremost catalyst in RAAS, it assumes an element in BP manipulation. It converts Ang to Ang I, that's thusly modified over by ACE to AngII. AngII has both immediate and backhanded impacts on BP. It straightforwardly makes blood vessel smooth muscle contract, prompting vasoconstriction and expanded BP. Ang II moreover invigorates the creation of aldosterone from the adrenal cortex, which causes the tubules of the kidneys to build reabsorption of sodium, with water following, in the end increasing plasma extent, and consequently BP. Renin inhibitor ties to renin; this coupling keeps the transformation of Ang to Ang I. Aliskiren is the first approved drug in the renin inhibitor class ${ }^{[79]}$ (Figures 2, 3).

\section{- Superiority of renin inhibitors over ACEIs}

ACEIs resulted in a decrease in AngII level; however they have a limited efficacy due to incomplete block of 
ACE and generation of AngII by other pathways. ACEI also interfere with bradykinin breakdown. Chronic ACEI use resulted in a return increase in circulating AgII due to interruption of AgII feedback on renin secretion ${ }^{[80]}$. However, renin inhibitors do not affect bradykinin release and block the action of AgII chronically at the AT-1 receptor $^{[80]}$.

Previous clinical study reported that renin inhibition by aliskiren resulted in the same effectiveness as ACEI with fewer side effects. ACEI produce severe cough due to kinins increase. Aliskiren considered a good substitute in this condition ${ }^{[81]}$. Added advantage for aliskiren is its extended $\mathrm{t} 1 / 2$ with ideal pharmacokinetic properties ${ }^{[82]}$.

\section{- Renoprotective impacts of renin inhibitors}

One month treatment with aliskiren (the principal drug in renin inhibitor class) after DN induction by STZ lead to euglycemia and normalized serum insulin when compared with diabetic group ${ }^{[48,83]}$. This impact was emphasized by the in-vitro experiment where aliskiren leads to dose-dependent stimulation of insulin secretion from isolated pancreatic islets of normal rats. Likewise, aliskiren synergized gliclazide-initiated insulin secretion in this in-vitro experiment. Furthermore, standardization of adiponectin when compared with the diabetic group was reported; this is related with bringing down insulin resistance. The stated antidiabetic impact of aliskiren on this investigation might be because of its capacity to empower insulin secretion or faded insulin resistance with the aid of normalizing serum adiponectin degree and antioxiidant effects ${ }^{[48]}$.

Habibi et al. (2008) ${ }^{[84]}$ exhibited that renin restraint by using aliskiren weakened insulin resistance in transgenic Ren2 rats that overexpress renin. on this manner, an achievable connection among coordinate renin hindrance by using aliskiren and insulin changed into proposed.

Renoprotective impacts of aliskiren were showed by its capacity to standardize BUN and serum creatinine ${ }^{[48]}$. Stanton 2003 and Schernthaner 2008 ${ }^{[85,86]}$ introduced that restraint of the main step in the RAAS (transformation of Ang to Ang I by using renin) by using aliskiren prompting extreme renoprotective effect isn't always just by way of blockading angiotensin II (Ang II) completely, but in addition via hindering the effects created thru activation of (pro) renin Receptor (P) RR. Likewise, aliskiren can diminish the gene expression of $(\mathrm{P}) \mathrm{RR}$ and may change the three-dimensional setup of renin ${ }^{[87]}$. Also aliskiren was accounted for to enhance glomerular filtration in past examinations ${ }^{[88,89]}$. Aliskiren additionally incerased serum adiponectin to ordinary level when compared with the diabetic group $^{[48]}$.

Prior investigations detailed that treatment with aliskiren brought about oxidation prevention impacts which were showed by critical reduction in renal MDA, serum NO and increment GSH, SOD. This proposes its renoprotective impact could be by means of combating oxidative stress created by STZ ${ }^{[48,90-92]}$.

Aliskiren decreased some antiinflammatory biomarkers, this showing its anti-inflammatory activity and this is steady with its renoprotecting activity. This was seen by critical decline in kidney TNF- $\alpha$ and TGF- $\beta$ when compared with diabetic group ${ }^{[48,83]}$. Aliskiren; as a renin inhibitor represses the binding of renin to renin receptors, which empowers the generation of inflammatory mediators as TGF- $\beta$, TNF- $\alpha$, PAI- 1 , fibronectin, and collagen through the Ang-independent extracellular signal-regulated kinase 1 and 2 pathways ${ }^{[93-95]}$.

Aliskiren also prevents TNF- $\alpha$ dependent apoptotic pathway by decreasing elevated TNF- $\alpha$ and decreasing caspase $3^{[48,96]}$. Inhibition of TGF- $\beta 1$ by aliskiren suggests that aliskiren prevents apoptosis and tubular atrophy through the inhibition of TGF- $\beta 1$ and TNF- $\alpha$ expression ${ }^{[48]}$.

Streptozotocin-induced histopathologi $\neg$ cal and ultrastructural changes were markedly improved by treatment with aliskiren. There was restoration of epithelial integrity. Attenuation of glumerosclerosis and tubulointerstitial fibrosis are considered as other important predictors of renal dysfunction ${ }^{[97]}$. This finding confirms the previous studies suggesting that RAAS blockade leads to preservation of podo $\neg$ cyte architecture, mitochondrial function and epithelial integrity ${ }^{[90,98,99]}$.

\section{CONCLUSIONS}

All the mentioned research papers above, reporting the novel mechanisms and benefits of targeting the RAAS by the use of ACEIs; ARB or direct renin inhibitors in glucose lowering, antioxidant, anti-inflammatory and renoprotection. They can be used as monotherapy or combination therapy in hypertensive-diabetic patients to protect them from DN. Also, new preclinical and clinical examinations are important to explore the safety of these agents and the effect of blend treatment.

\section{COMPLIANCE WITH ETHICAL STANDARDS}

- No Funding sources available

- Authors declare that they have no conflict of interest.

- This article does not contain any studies with human participants or animals performed by the author.

\section{LIST OF ABBREVIATIONS}

$\begin{array}{ll}\text { AT2R } & \text { Angiotensin type 2 receptor. } \\ \text { ARBs } & \text { Angiotensin receptor blockers. } \\ \text { DN } & \text { Diabetic nephropathy. } \\ \text { ET 1 } & \text { Endothelin } 1 . \\ \text { eNOS } & \text { Endothelial nitric oxide synthase. } \\ \text { ESRD } & \text { End stage renal disease. } \\ \text { GLUT2 } & \text { Glucose transporter } 2 .\end{array}$




$\begin{array}{ll}\text { GSH } & \text { Reduced glutathione. } \\ \text { H } & \text { Hour } \\ \text { IL6 } & \text { Interleukin } 6 . \\ \text { IgA } & \text { Immunoglobulin A. } \\ \text { IgG } & \text { Immunoglobulin G. } \\ \text { MDA } & \text { Malondialdehyde. } \\ \text { RAAS } & \text { Rennin angiotensin aldosterone system. } \\ \text { ROS } & \text { Reactive Oxygen Species. } \\ \text { RR } & \text { Renin receptor. } \\ \text { SOD } & \text { Superoxide dismutase activity. } \\ \text { STZ } & \text { Streptozotocin. } \\ \text { TBARS } & \text { Thiobarbituric acid reactive substance. } \\ \text { TNF- } \alpha & \text { Tumor necrosis factor - } \alpha . \\ \text { CONFLICT } \text { OF INTEREST }\end{array}$

There are no conflicts of interest.

\section{REFERENCES}

1. J.F. Blicklé, J. Doucet, T. Krummel, T. Hannedouche Diabetic nephropathy in the elderly. Diabetes Metab., 33 (2007), S40-55 Review.

2. G.R. Casey, M. Joyce, R.G. Nagle, G. Chen, D. Hayes. Pravastatin modulates early diabetic nephropathy in an experimental model of diabetic renal disease. J Surg Res., 123 (2004), 176-181.

3. M. Kurus, M. Esrefoglu, A. Bay, F. Ozturk. Protective effect of oral L-arginine supplementation on ciclosporin induced nephropathy in rats. Int Urol Nephrol., 37 (2005), 587-594.

4. N. Koike, T. Takamura, S. Kaneko. Induction of reactive oxygen species from isolated rat glomeruli by protein kinase $\mathrm{C}$ activation and TNF-stimulation, and effects of a phosphodiesterase inhibitor. Life Sci., 80 (2007), 1721-1728.

5. L. Tain, G. Freshour, A. Dikalova, K. Griendling, C. Baylis. Vitamin E reduces glomerulosclerosis, restores renal neuronal NOS, and suppresses oxidative stress in the 5/6 nephrectomized rat. Am J Physiol Renal Physiol., 292 (2007), F1404-F1410.

6. B. Hocher, A. Schwarz, D. Reinbacher, J. Jacobi, A. Lun, F. Priem, et al. Effects of endothelin receptor antagonists on the progression of diabetic nephropathy. Nephron. 87 (2001), 161-169.

7. E. Y. Lee, M. S. Shim, M. J. Kim, S. Y. Hong, Y. Shin, C. H. Chung. Angiotensin II receptor blocker attenuates overexpression vascular endothelial growth factor in diabetic podocytes. Exp Mol Med., 1 (2004), 65-70.

8. A. Tahara, J. Tsukada, Y. Tomura, T. Suzuki, T. Yatsu, M. Shibasaki. Vasopressin stimulates the production of extracellular matrix by cultured rat mesangial cells. Clin Exp Pharmacol Physiol., 35 (2008), 586-593.
9. P. N. Sidhart, F. D. Wagner, H. Bohnemeier, A. Jungnik, A. Halabi, S. Dingemanse. Pharmacodynamics and pharmacokinetics of the urotensin II receptor antagonist palosuran in macroalbuminuric, diabetic patients. Clin Pharmacol Ther., 80 (2006), 246-256.

10. Y. Matsumoto, S. Ueda, S. Yamagishi, K. Matsuguma, Shibata R, Fukami K, Matsuoka H, et al. Dimethyl arginine dimethyl aminohydrolase prevents progression of renal dysfunction by inhibiting loss of peritubular capillaries and tubulointerstitial fibrosis in a rat model of chronic kidney disease. J Am Soc Nephrol., 18 (2007), 1365-1367.

11. P. G. Valles, W. Manucha, L. Carrizo, P. J. Vega, A. Seltzer, C. Ruete. Renal caveolin-1 expression in children with unilateral ureteropelvic junction obstruction. Pediatr Nephrol., 22 (2007), 273-283.

12. C. J. Won, C. S. Kim, S. B Kim, S. K. Park, J. S. Park, S. K. Lee. C-reactive protein induces NF- $\kappa$ activation through intracellular calcium and ROS in human mesangial cells. Nephron Exp Nephrol., 101(2005), e165-e172.

13. MP-S. Lee, D. Orlov, G. Sweeney. Leptin induces rat glomerular mesangial cell hypertrophy, but does not regulate hyperplasia or apoptosis. Int J Obes., 29 (2005), 1395-1401.

14. H. J. Zhao, S. Wang, H. Cheng, M. Z. Zhang, T. Takahashi, A. B. Fogo, M. D. Breyer, R. C. Harris. Endothelial nitric oxide synthase deficiency produces accelerated nephropathy in diabetic mice. J Am Soc Nephrol., 17 (2006), 2664-2669.

15. J. Singh, S. Budhiraja, H. Lal, B. R. Arora. Renoprotection by telmisartan versus benazepril in streptozotocin induced diabetic nephropathy. Iran J Pharmacol Ther., 5 (2006), 135-139.

16. D. I. Shah, M. Singh. Inhibition of protein tyrosin phosphatase improves vascular endothelial dysfunction. Vascul Pharmacol., 44 (2006), 177-182.

17. C. Szabo. Roles of poly (ADP-ribose) polymerase activation in the pathogenesis of diabetes mellitus and its complications. Pharmacol Res., 52 (2005), 60-67.

18. T. Yokozawa, T. Nakagawa, W. Wakaki, F. Koizumi. Animal model of diabetic nephropathy. Exp Toxicol Pathol., 53 (2001), 359-363.

19. F. Y. Chow, D. J. Nikolic-Paterson, R. C. Atkins, G. H. G. H. Tesch. Macrophages in streptozotocin-induced diabetic nephropathy: potential role in renal fibrosis. Nephrol Dial Transplant., 19 (2004), 2987-2996.

20. M. S. Bitara, S. Wahida, S. Mustafa, E. Al-Saleh, G. S. Dhaunsi, F. Al-Mulla. Nitric oxide dynamics and endothelial dysfunction in type 2 model of genetic diabetes. Eur J Pharmacol., 511 (2005), 53-64. 
21. J.Lloveras. Use of cyclosporine in renal transplantation. Trans Proc. 36 (2004), 107S-113S.

22. M. LaSpina, S. Tripathi, L. A. Gatto, D. Bruch, K. G. Maier, D. S. Kittur. An interleukin-6neutralizing antibody prevents cyclosporine-induced nephrotoxicity in mice. J Surg Res., 148 (2008), 121-125.

23. H. Hahn, Y. S. Park, S. Ha, H. Cheong, Y. Choi. Age-related differences in adriamycin-induced nephropathy. Pediatr Nephrol., 19 (2004), 761-766.

24. M. Mune, H. Otani, S. Yukawa. Effects of antioxidants on kidney disease. Mech Ageing Dev., 123 (2002), 1041-1046.

25. T. A. Gvozdenko, T. E. Novgorodtseva, O. G. Vostrikova, V. G. Kapitonova. Simulation of electrolyte nephropathy in rats. Bull Exp Biol Med., 138 (2004), 238-240.

26. R. A. Corley, D. M. Wilson, G. C. Hard, K. E. Stebbins, M. J. Bartels, J. J. Soelberg, et al. Dosimetry considerations in the enhanced sensitivity of male wistar rats to chronic ethylene glycol-induced nephrotoxicity. Toxicol Appl Pharmacol., 228 (2008), 165-178.

27. V. K. Kumar, M. U. R. Naidu, A. Shifow, K. S. Ratnakar. Probucol protects against gentamicininduced nephrotoxicity in rats. Indian J Pharmacol., 32 (2000), 108-113.

28. P. E. Leffler, T. Jin, G. F. Nordberg. Nephrotoxic impact of multiple short-interval cadmium-metallothionein injections in the rat. Toxicology. 112 (1996), 151-156.

29. K. Uriu, K. Kaizu, N. Komine, M. Ikeda, Y. L. Qie, O. Hashimoto, et al. Renal hemodynamics in rats with cadmium-induced nephropathy. Toxicol Appl Pharmacol. 150 (1998) 76-85.

30. M. Junnila, T. Rahko, A. Sukura, L. A. Lindberg. Reduction of carbon tetrachloride-induced hepatotoxic effects by oral administration of betaine in male hanwistar rats: a morphometric histological study. Vet Pathol., 37 (2000), 231-238.

31. M. Ogeturk, I. Kus, A. Kavakli, J. Oner, A. Kukner, M. Sarsilmaz. Reduction of carbon tetrachlorideinduced nephropathy by melatonin administration. Cell Biochem Funct., 23 (2005), 85-92.

32. H. Yanagisawa, N. Yamazaki, G. Sato, O. Wada. L-Arginine treatment may prevent tubulointerstitial nephropathy caused by germanium dioxide. Kidney Int., 57 (2000), 2275-84.

33. B. Sampaio-Maia, M. Moreira-Rodrigues, P. Serrao, M. Pestana. Blunted renal dopaminergic system activity in $\mathrm{HgCl} 2$-induced membranous nephropathy. Life Sci., 78 (2006), 1246-1255.
34. S. Y. Saad, M. M. Arafah, T. A. Najjar. Effect of mycophenolate mofetil on cisplatin-induced renal dysfunction in rats. Cancer Chem Pharmacol., 59 (2007), 455-460.

35. Q. Jia, H. R. Zhou, M. Bennink, J. J. Pestka. Docosahexaenoic acid attenuates mycotoxin-induced immunoglobulin A nephropathy, interleukin-6 transcription, and mitogen-activated protein kinase phosphorylation in mice. J Nutr., 134 (2004), 3343-3349.

36. B. Jim, M. Ghanta, A. Qipo, Y. Fan, P. Y. Chuang, H. W. Cohen, D. B. Thomas and J. C. He. Dysregulated nephrin in diabetic nephropathy of type 2 diabetes: a cross sectional study, PLoS One. 7 (2012), 5.

37. Y. Togashi and Y. Miyamoto. Urinary cystatin C as a biomarker for diabetic nephropathy and its immunohistochemical localization in kidney in Zucker diabetic fatty (ZDF) rats. Exp Toxicol Pathol., 65(5) (2013), 615-622.

38. M. E. Hellemons, J. Kerschbaum, S. J. Bakker, H. Neuwirt, B. Mayer, G. Mayer, et al. Validity of biomarkers predicting onset orprogression of nephropathy in patients with Type 2 diabetes: a systematic review. Diabet Med., 29 (2012), 567-577.

39. R. Tofik, O. Torffvit, B. Rippe and O. Bakoush. Urine IgM-excretion as a prognostic marker for progression of type 2 diabetic nephropathy. Diabetes Res Clin Pract., 95 (2012), 139-144.

40. P. Sthaneshwar and S. P. Chan. Urinary type IV collagen levels in diabetes mellitus. Malays J Pathol., 32 (2010), 43-47.

41. M. Vestra, A. Masiero, A. M. Roiter, A. Saller, G. Crepaldi and P. Fioretto. Is podocyte injury relevant in diabetic nephropathy? Studies in patients with type 2 diabetes. Diabetes., 52 (2003), 1031-1035.

42. C. Wang, C. Li, W. Gong and T. Lou. New urinary biomarkers for diabetic kidney disease. Biomark Res., 1 (2013), 9 .

43. N. Ohara, O. Hanyu, S. Hirayama, O. Nakagawa, Y. Aizawa, S. Ito, et al. Hypertension increases urinary excretion of immunoglobulin $\mathrm{G}$, ceruloplasmin and transferrin in normoalbuminuric patients with type 2 diabetes mellitus. J Hypertens., 32 (2014), 432-438.

44. S. W. Ha, H. J. Kim, J. S. Bae, G. H. Jeong, S. C. Chung, J. G. Kim, et al. Elevation of urinary betaig-h3, transforming growth factor-beta-induced protein in patients with type 2 diabetes and nephropathy. Diabetes Res Clin Pract., 65 (2004), 167-173.

45. E. Korpinen, A. M. Teppo, L. Hukkanen, H. K. Akerblom, C. Gronhagen-Riska and O. Vaarala. Urinary transforming growth factor-betal and alpha1microglobulin in children and adolescents with type 1 diabetes. Diabetes Care., 23 (2000), 664-668. 
46. K. Sharma, F. N. Ziyadeh, B. Alzahabi, T. A. McGowan, S. Kapoor, B. R. Kurnik, P. B. Kurnik, et al. Increased renal production of transforming growth factor-beta 1 in patients with type 2 diabetes. Diabetes. 46 (1997), 854-859.

47. R. E. Gilbert, A. Akdeniz, T. J. Allen, and G. Jerums. Urinary transforming growth factor-beta in patients with diabetic nephropathy: implications for the pathogenesis of tubulointerstitial pathology. Nephrol Dial Transplant., 16 (2001), 2442-2443.

48. A. M. Mahfoz, H. A. Abd El-Latif, L. A. Ahmed, N. M. Hassanein, A. A. Shoka. Anti-diabetic and renoprotective effects of aliskiren in streptozotocininduced diabetic nephropathy in female rats. Naunyn Schmeidberg Archieves of pharmacology. 12 (2016), 1315-1324.

49. Y. Aso, K. Takanashi, K. Sekine, N. Yoshida, K. Takebayashi K, Yoshihara, et al. Dissociation between urinary pyrraline and pentosidine concentrations in diabetic patients with advanced nephropathy. J Lab Clin Med., 144 (2004), 92-99.

50. M. Serdar, E. Sertoglu, M. Uyanik, S. Tapan, K. Akin, C. Bilgi, I. Kurt. Comparison of 8-hydroxy2'-deoxyguanosine (8-OHdG) levels using mass spectrometer and urine albumin creatinine ratio as a predictor of development of diabetic nephropathy. Free Radic Res. 46 (2012), 1291-1295.

51. X. Q. Tian, L. M. Zhao, J. P. Ge, Y. Zhang and Y. C. Xu. Elevated urinary level of vitamin D-binding protein as a novel biomarker for diabetic nephropathy. Exp Ther Med., 7 (2014), 411-416.

52. R. N. Moresco, M. B. Sangoi, J. A. Carvalho, E. Tatsch and G. V. Bochi. Diabetic nephropathy: traditional to proteomic markers. Clin Chim Acta, 421 (2013), 1730 .

53. E. J. Henriksen, S. Jacob, T. R. Kinnick, E. B. Youngblood, M. B. Schmit, G. J. Dietze. ACE inhibition and glucose transport in insulin resistant muscle: roles of bradykinin and nitric oxide. Am J Physiol Endocrinol Metab., 277 (1999), 332-336.

54. D. G. Passos-Silva, T. Verano-Braga, R. A. Santos. Angiotensin- (1-7): beyond the cardio-renal actions. Clin Sci (Lond)., 124 (2013), 443-456.

55. P. S. Leung. Pancreatic renin-angiotensin system: a novel target for the potential treatment of pancreatic diseases?. JOP.J Pancreas. 4 (2003), 89-91.

56. A. D. Kloet, E. G. Krause, S. C. Woods. The renin angiotensin system and the metabolic syndrome. Physiol Behav., 100 (2010), 525-534.

57. J. M. Luther, N. J. Brown. The renin-angiotensinaldosterone system and glucose homeostasis. Trends Pharmacol Sci., 32 (2011), 734-739.
58. D. A. Babu, T. G. Deering, R. G. Mirmira. A feat of metabolic proportions: Pdx1 orchestrates islet development and function in the maintenance of glucose homeostasis. Mol Genet Metab., 92 (2007), 43-55.

59. V. Navarro-Tableros, T. Fiordelisio, A. HernandezCruz, Hiriart. Physiological development of insulin secretion, calcium channels, and GLUT2 expression of pancreatic rat beta-cells. Am J Physiol Endocrinol Metab., 292 (2007), E1018-E1029.

60. A. S. Bernardo, C. W. Hay, K. Docherty. Pancreatic transcription factors and their role in the birth, life and survival of the pancreatic beta cell. Mol Cell Endocrinol., 294 (2008), 1- 9.

61. P. Zimmet, K. G. Alberti, J. Shaw. Global and societal implications of the diabetes epidemic. Nature, 414 (2001), 782-787.

62. R. Padwal, A. Laupacis. Antihypertensive therapy and incidence of type 2 diabetes: a systematic review. Diabetes Care, 27 (2004), 247-255.

63. S. Yusuf, M. A. Pfeffer, K. Swedberg, C. B. Granger, P. Held, J. J. McMurray, et al. Effects of candesartan in patients with chronic heart failure and preserved leftventricular ejection fraction: the CHARM-Preserved Trial. Lancet, 362 (2003), 777-781.

64. S. Julius, S. E. Kjeldsen, M. Weber, H. R. Brunner, S. Ekman, L. Hansson, et al. Outcomes in hypertensive patients at high cardiovascular risk treated with regimens based on valsartan or amlodipine: the VALUE randomized trial. Lancet, 363 (2004), 20222031.

65. E. Bernobich, L. Angelis, C. Lerin, G. Bellini. The role of the angiotensin system in cardiac glucose homeostasis: therapeutic implications. Drugs, 62 (2002), 1295-1314.

66. S. I. McFarlane, A. Kumar, J. R. Sowers. Mechanisms by which angiotensinconverting enzyme inhibitors prevent diabetes and cardiovascular disease. Am J Cardiol., 91 (2003), 30H-37H.

67. T. Shiuchi, M. Iwai, H. S. Li, L. Wu, L. J. Min, J. M. Li, et al. Angiotensin II type 1 receptor blocker valsartan enhances insulin sensitivity in skeletal muscles of diabetic mice. Hypertension, 43 (2004), 1003-1010.

68. H. C. Gerstein. Reduction of cardiovascular events and microvascular complications in diabetes with ACE inhibitor treatment: HOPE and MICRO HOPE. Diabetes Metab Res Rev., 18 (2002), S82-S85.

69. J. Damas, C. Hallet, P. J. Lefebvre. Changes in blood glucose and plasma insulin levels induced by bradykinin in anaesthetized rats. Br J Pharmacol., 134 (2001), 1312-1318. 
70. T. Shiuchi, T. X. Cui, L. Wu, H. Nakagami, Y. TakedaMatsubara, M. Iwai, et al. ACE inhibitor improves insulin resistance in diabetic mouse via bradykinin and NO. Hypertension, 40 (2002), 329-334.

71. A. Kudoh, A. Matsuki. Effects of angiotensinconverting enzyme inhibitors on glucose uptake. Hypertension, 36 (2000), 239-244.

72. G. Paolisso, M. R. Tagliamonte, A. Gambardella, D. Manzella, P. Gualdiero, G. Varricchio, et al. Losartan mediated improvement in insulin action is mainly due to an increase in non-oxidative glucose metabolism and blood flow in insulin-resistant hypertensive patients. J Hum Hypertens., 11 (1997), 307-312.

73. R. Fogari, A. Zoppi, L. Corradi, P. Lazzari, A. Mugellini, P. Lusardi. Comparative effects of lisinopril and losartan on insulin sensitivity in the treatment of non-diabetic hypertensive patients. Br J Clin Pharmacol., 46 (1998a), 467-471.

74. R. Fogari, A. Zoppi, P. Lazzari, P. Preti, A. Mugellini, L. Corradi, et al. ACE inhibition but not angiotensin II antagonism reduces plasma fibrinogen and insulin resistance in overweight hypertensive patients. J Cardiovasc Pharmacol., 32 (1998b), 616-620.

75. R. Fogari, A. Zoppi, P. Preti, E. Fogari, G. Malamani, A. Mugellini. Differential effects of ACE-inhibition and angiotensin II antagonism on fibrinolysis and insulin sensitivity in hypertensive postmenopausal women. Am J Hypertens., 14 (2001), 921-926.

76. F. Folli, M. J. Saad, L. Velloso, H. Hansen, O. Carandente, E. P. Feener, et al. Crosstalk between insulin and angiotensin II signalling systems. Exp Clin Endocrinol Diabetes, 107 (1999), 133-139.

77. L. H. Lindholm, H. Ibsen, K. Borch-Johnsen, M. H. Olsen, K. Wachtell, B. Dahlöf, R. B. Devereux, et al. Risk of new-onset diabetes in the Losartan Intervention for Endpoint Reduction in Hypertension Study. J Hypertens., 20 (2002), 1879-1886.

78. M. C. Michel, H. R. Brunner, C. Foster, and Y. Huo. Angiotensin II type 1 receptor antagonists in animal models of vascular, cardiac, metabolic and renal disease. Pharmacology and Therapeutics. 164 (2016), $1-81$.

79. C. M. Baldwin, G. L. Plosker. Aliskiren/ hydrochlorothiazide combination: in mild to moderate hypertension. Drugs. 69 (2009), 833-841.

80. J. L. Wilkinson-Berka. Renoprotective and antihypertensive effects of combined valsartan and perindopril in progressive diabetic nephropathy in the transgenic (mRen-2) 27 rat. Nephrol Dial Transplant., 16 (2001), 1343-1349.

81. Michel Azizi, Joël Ménard. Combined Blockade of the Renin-Angiotensin System With AngiotensinConverting Enzyme Inhibitors and Angiotensin II
Type 1 Receptor Antagonists. Circulation, 109 (2004), 2492-2499.

82. H. K. Nyathani, P. Srirangam, K. M. Chinnala, V. S. Jenugu. Renoprotective Effects of Combined Aliskiren and Valsartan in Progressive Diabetic Nephropathy in Rats International Journal of Pharmaceutical Sciences and Nanotechnology, 3 (2011), 1276-1286.

83. S. Gandhi, B. P. Srinivasan, A. S. Akarte. Aliskiren improves insulin resistance and ameliorates diabetic renal vascular complications in STZ-induced diabetic rats. Journal of Renin-Angiotensin-Aldosterone System, 14 (2013), 3-13.

84. J. Habibi, A. Whaley-Connell, M. R. Hayden, V. G. Marco, R. Schneider, S. D. Sowers, et al. Renin inhibition attenuates insulin resistance, oxidative stress, and pancreatic remodeling in the transgenic Ren2 rat. Endocrinol., 149 (2008), 5643-5653.

85. A. Stanton, C. Jensen, J. Nussberger, E. Brien. Blood pressure lowering in essential hypertension with an oral renin inhibitor, aliskiren. Hypertens., 42 (2003), 1137-1143.

86. G. Schernthaner. Dual inhibition with losartan and aliskiren: a promising therapeutic option for type 2 diabetic nephropathy. Nat Clin Pract Nephrol., 4 (2008), 656-657.

87. R. Nistala, Y. Wel, J. Sowers, A. Whaley-Connell. Renin-angiotensin-aldosterone system-mediated redox effects in chronic kidney disease. Transl Res., 153 (2008), 102-113.

88. J. M. Wood, J. Maibaum, J. Rahuel, M. G. Grütter, N. C. Cohen, V. Rasetti, et al. Structure-based design of aliskiren, a novel orally effective renin inhibitor. Biochem Biophys Res Commun., 308 (2003), 698705 .

89. A. Rashikh, K. K. Pillai, S. J. Ahmad, M. Akhtar, A. K. Najmi. Aliskiren alleviates doxorubicin-induced nephrotoxicity by inhibiting oxidative stress and podocyte injury. J Renin Ang. Ald. Syst., 14 (2013), 14-22.

90. A. Whaley-Connell, R. Nistala, J. Habibi, R. I. Schneider, M. S. Johnson, R. Tilmon, et al. Sowers Comparative effect of direct renin inhibition and AT1R blockade on glo $\neg$ merular filtration barrier injury in the transgenic Ren2 rat. Am J Physiol Renal Physiol., 298 (2010), F655-F661.

91. K. C. Lee, C. C. Chan, Y. Y. Yang, Y. C. Hsieh, Y. H. Huang, H. C. Lin. Aliskiren attenuates steatohepatitis and increases turnover of hepatic fat in mice fed with a methionine and choline deficient diet. PLoS One. 8 (2013), 1-11.

92. O. N. Al-Harbi, F. Imam, M. M. Al-Harbi, M. Iqbal, A. Nadeem, O. A. Al-Shahrah, et al. Treatment with aliskiren ameliorates tacrolimus-induced 
nephrotoxicity in rats. Journal of the ReninAngiotensin-Aldosterone System, (2014), 1-8.

93. Y. Huang, N. A. Noble, J. Zhang, C. Xu, W. A. Border. Renin-stimulated TGF-betal expression is regulated by a mitogen-activated protein kinase in mesangial cells. Kidney Int., 72 (2007), 45-52.

94. A. Gradman, R. Kad. Renin inhibition in hypertension. J Am Coll Cardiol., 51 (2008), 519-528.

95. Z. Abassi, J. Winaver, G. Feuerstein. The biochemical pharmacology of renin inhibitors: implications for translational medicine in hypertension, diabetic nephropathy and heart failure: expectations and reality. Biochem Pharmacol., 78 (2009), 933-940.

96. B. E. Hui, I. J. Kim, S. Y. Joo, E. Y. Kim, J. S. Choi, Chang Seong Kim, Seong Kwon Ma, et al. Renoprotective effects of the direct renin inhibitor aliskiren on gentamicin-induced nephrotoxicity in rats. Journal of the Renin-Angiotensin Aldosterone System. BioEssays., 25 (2013), 888-896.

97. D. J. Kelly, Y. Zhang, G. Moe, G. Naik, R. E. Gilbert. Aliskiren, a novel renin inhibitor, is renoprotective in a model of advanced diabetic nephropathy in rats. Diabetologia., 50 (2007), 2398-2404.

98. S. A. Mifsud, T. J. Allen, J. F. Bertram, U. L. Hulthen, D. J. Kelly, M. E. Cooper, et al. Podocyte foot pro $\neg$ cess broadening in experimental diabetic nephropathy: Amelioration with renin-angiotensin blockade. Diabetologia., 44 (2001), 878-882.

99. A. C. Huby, M. P. Rastaldi, K. Caron, Oliver Smithies, J. C. Dussaule, C. Chatziantoniou. Restoration of podo $\neg$ cyte structure and improvement of chronic renal disease in transgenic mice overexpressing renin. PLoS One. 4 (2009), 1-9. 